\title{
Development of Lesson Plans Utilizing VR Experiencing Classroom in a Smart Elementary School
}

\author{
Heejeon Suh \\ Tongmyong University \\ Busan, 608-711, Republic of Korea \\ heejeon.suh@gmail.com
}

\begin{abstract}
This study aims to develop lesson plans using mixed reality contents in VR experiencing
\end{abstract} classroom. For the purpose of this study, we analyed 10 mixed reality contents, VR experiencing classroom environment, and curriculum in C smdrt model school in KOREA. Moreover, we derived three teaching-learning models and applied them to experience learning activity design using mixed reality contents. Three models included role play model, group investigation model, and task based anguage teaching model. As the result of this study, we developed specific lesson plans based on three models. For further study, it is needed to apply experience learning activities to elementary class, and to evaluate the effectiveness of these lessons.

Keywords: Mixed Reality Contents, VR Experiencing Classroom, Lesson Plan

\section{Introduction}

The smart and virtuay technology is influencing conventional teaching methods in school education. In Singapore, througha future project such as 'Future Schools@ Singapore,' Beacon future school provides a 3D virtual learning simulation environment supporting customized curriculum of elementary school. In Korea, 14 Smart model schools were appointed from 2012. Celementary school in Sejong City is providing virtual reality (VR) experiencing classroom to which mixed technologies are applied. Finland and England also suggested and built future model schools. Mixed reality (MR) technology is a kind of virtual reality (VR) which makes users perceive mixed images by showing the world incorporating real world vith virtual world with computer graphics. It is a computer interface technology interacting computers by manipulating virtual objects through actions of users in real time. [1, 2]. Hew and Cheung [3] classified utilization aspects of virtual world as communication space, simulation of space, experiential space. In MR based learning environments, learners can experience problems in concrete contexts and can experience feedbacks and observe concrete results through interactions by actual manipulations. As learning processes are worked by learning behaviors, behaviors trigger explorative activities and lead to meaningful learning. MR makes learners' experience more "engaging" and promotes active and interactive learning $[4,5]$. The initial study of utilizing MR technology to class have shown that it was applied to elementary school classes through science, English and mathematic contents which were developed by adding virtual objects on existing textbooks [1]. Previous studies on the effects of MR experiencing learning where students received 8-week classes using augmented reality contents on 'King Midas' through the process of storytelling, quest, and role play showed significantly higher activeness in action and language [4]. When looking into the studies on 
children's response in juvenile drama activities based on MR and robot technology, it was found that children did not feel difficulties in understanding roles and functions of marker and augmented reality technology and manipulating them, and that they thought it interesting that various object images were combined with different backgrounds and being enforced [5]. Huang, Rauch, and Liaw [6] suggested five constructivist instructional principles in VR learning environments: situated learning, role playing, cooperative learning, problem-based learning, and creative learning. These principles can support in developing and applying MR learning environment. But elementary lesson plans for collective instruction with a large screen VR system is not enough. Therefore, this study aims to develop lesson plans using mixed reality contents in VR experiencing classroom based on teaching-learning models and suggest MR contents and VR experiencing classroom environment supporting these lessons.

\section{Research Method}

For the purpose of this study, first, we reviewed the literature and related studies. Second, we analyzed MR contents of $\mathrm{C}$ elementary school and $\mathrm{R}$ experiencing classroom. We took a video on student-content interaction processes by operating MR contents. Third, we performed interviews with teachers responsible for $V R$ experiencing classroom. Forth, we developed practical units for subjects and learning activities based on teaching models in the class. Lastly, we modified and supplemented them according to the review by an elementary school teacher and an educational technology'expert $\ell$

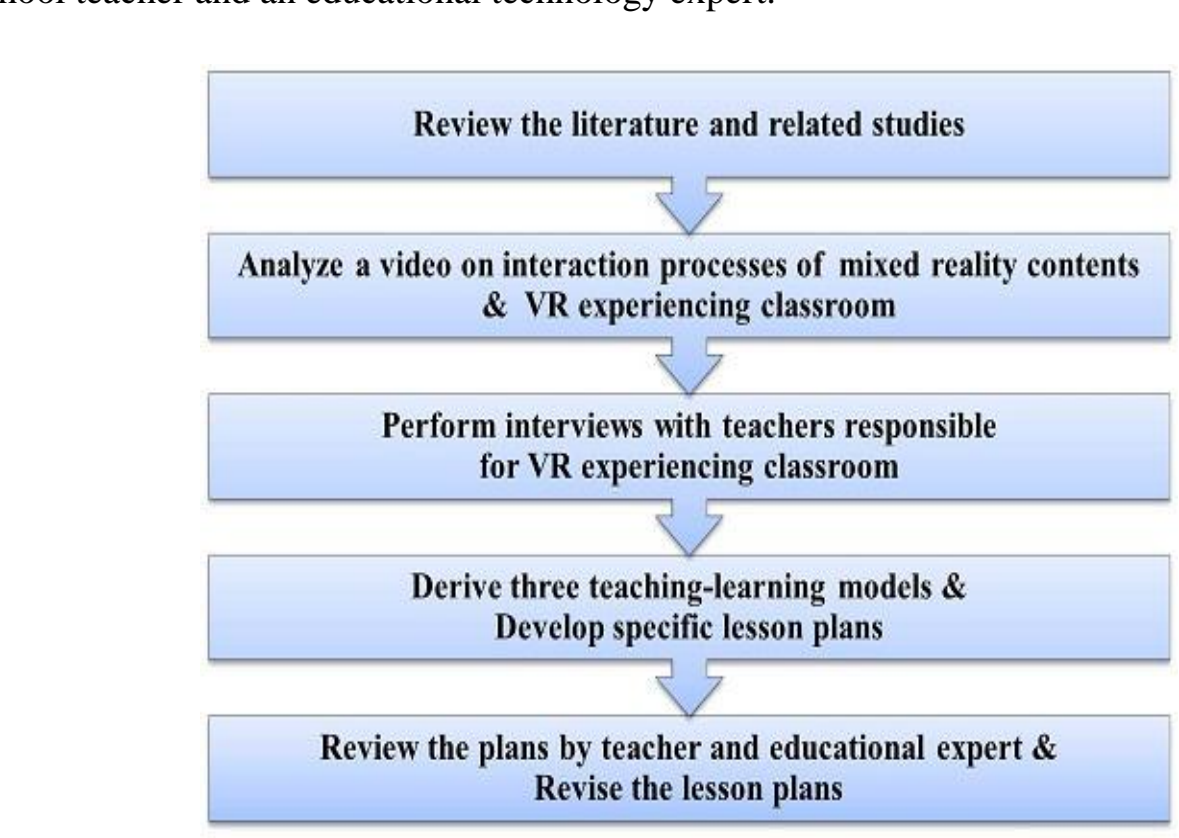

Figure 1. Research Procedures

\section{VR Experiencing Classroom Environment}

\subsection{Mixed Reality Contents}

Mixed reality contents allow learners participate in 3D virtual contents based on mixed reality technology and experience learning through interactions with learning contents. In $\mathrm{C}$ elementary school, 10 kinds of MR contents were in place. Three Korean language contents consisted of fairy tales such as 'Three Piglet Brothers', 'Old Man with a Lump', and 'The 
Wizard of OZ'. Science contents included 'The Ants', 'The Earth and the Moon', and 'Solar System'. English contents were 'Boston Subway', 'Egypt', 'Greek and Roman Antiquities', and 'Paintings'.

\subsection{VR experiencing Classroom Environment}

The VR experiencing classroom established in C elementary school provided a mixed reality experiencing contents system and an operational program for teachers. As a Kinect camera was implemented on the large MR contents screen and it perceived a student in the Action Zone, it synthesized the contents and the student and projected the synthesized image on the screen. Students can interact by selecting virtual contents using their hands. As there is an electronic blackboard on the opposite side of MR contents screen, teachers can integrate the VR experiencing lessons into ordinary lessons.
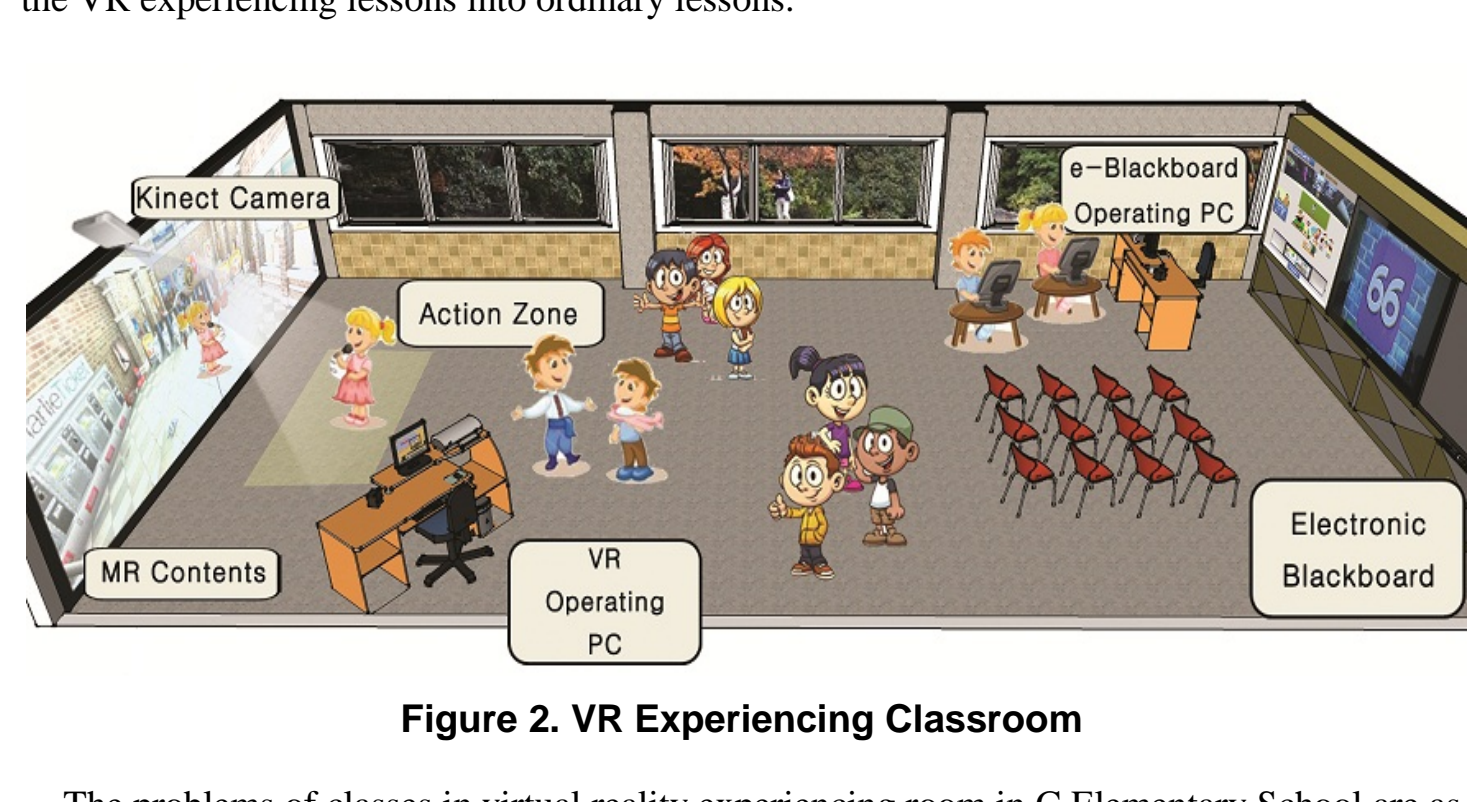

The problems of classes in virtual reality experiencing room in C Elementary School are as follows. First, actual usability is very low considering the number of contents established in the school and only neacher was using the system. Second, the teacher had to lead the class while he/she was operating the contents program of virtual reality experiencing system, and therefore problems were made as the location of the teacher had to be fixed at system operating PC. Third, as Kinect can only recognize one or two students in the Action Zone, rest of stadents had to watch them experiencing virtual reality.

\section{Developing Experience Lesson Plans Using MR Contents}

We applied three teaching-learning models (role play model, group investigation model, and task based language teaching model) to experience lesson plan design using mixed reality contents [7]. Strategies of lesson development using MR contents included that 1) all student can participate in experience activities in VR classroom,2) consider the relation with standard curriculum of elementary schools, 3) For low grade students, take advantage of a number of physical play, role play, chanting, games, songs, art activities, etc., and 4) For high grade students, include high-level research presentation and cooperative learning. 


\subsection{Role Play Model}

Role play is an effective teaching method for affecting individual attitudes and developing interpersonal skills through dramatizations [8]. Through role play using MR contents, students can understand the given problems and solve the problems by experiencing situations indirectly through the process of setting virtual situations and performing roles. Three kinds of lessons were planned based on role playing model focusing on fairy tales MR contents such as 'Three Piglet Brothers', 'Old Man with a Lump', and 'The Wizard of OZ'. Role play lessons are performed through setting situations, preparation and practice, performance and evaluation. This model can develop sensitive values or emotions, problem solving capabilities, communication capabilities and expression capabilities by making them explore problem situations and discussing their roles [9].

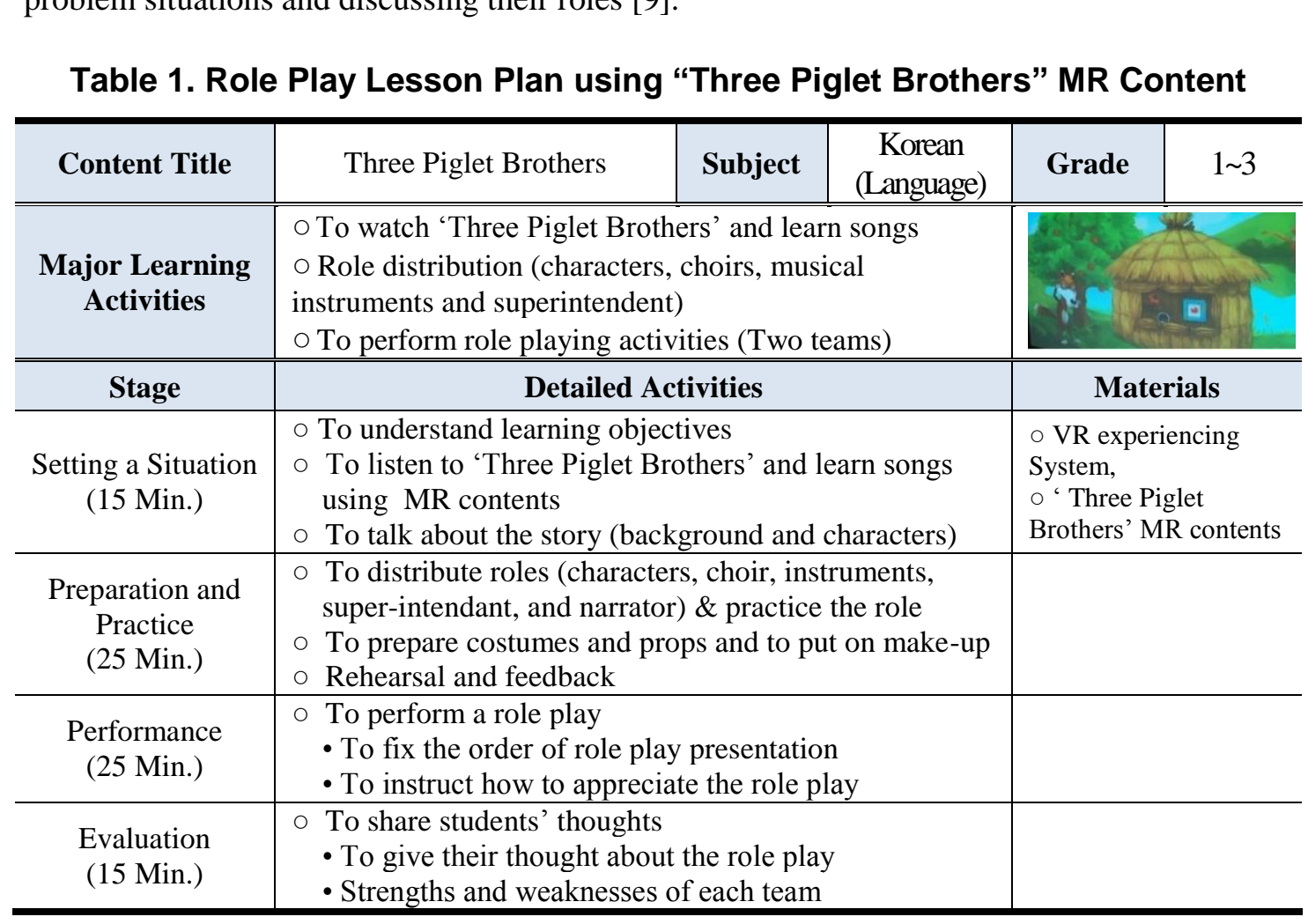

\subsection{Group Investigation (GI) Model}

Group Investigation (GI) is one type of Cooperative Learning. In GI, students can select an interest topic, organize groups, plan and implement an investigation, and put together the results and findings into a group presentation for other students in the class [10]. GI lesson consists of 6 stages such as topic and teams, planning of investigation, action, preparation of final report, presentation, and assessment/evaluation. 


\section{Table 2. Group Investigation Lesson Plan Using "The Earth and the Moon" Content}

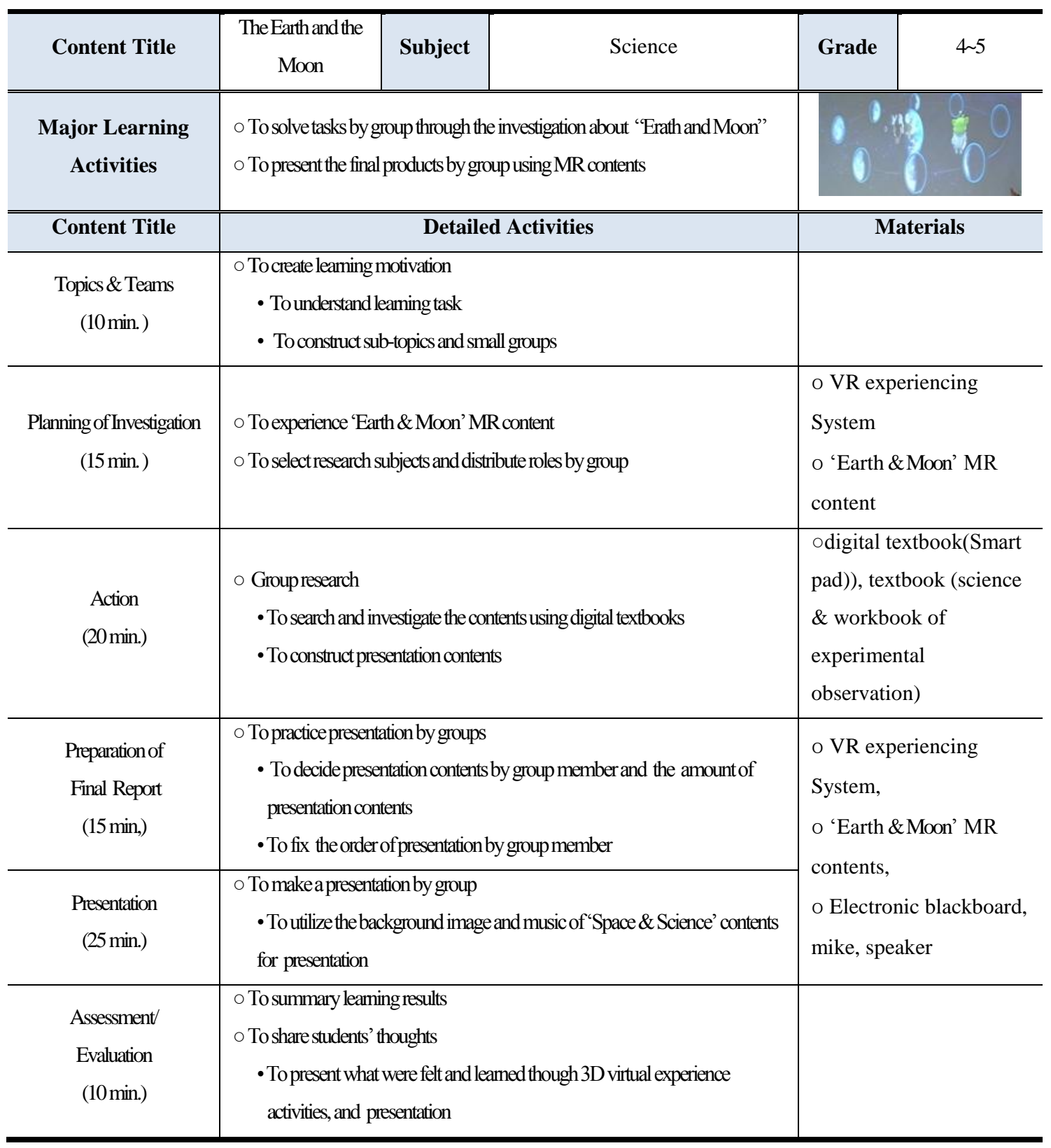

\subsection{Task Based Language Teaching (TBLT) Model}

Task Based Language Teaching (TBLT) is placed on asking students to perform meaningful tasks using the target language in real situation. Tasks can include visiting museum and riding Boston subway [11]. TBLT model has 3 stages such as pre-task activities, task activities, post-test activities. 


\section{Table 3. Task Based Language Teaching (TBLT) Lesson Plan Using "Egypt” Content}

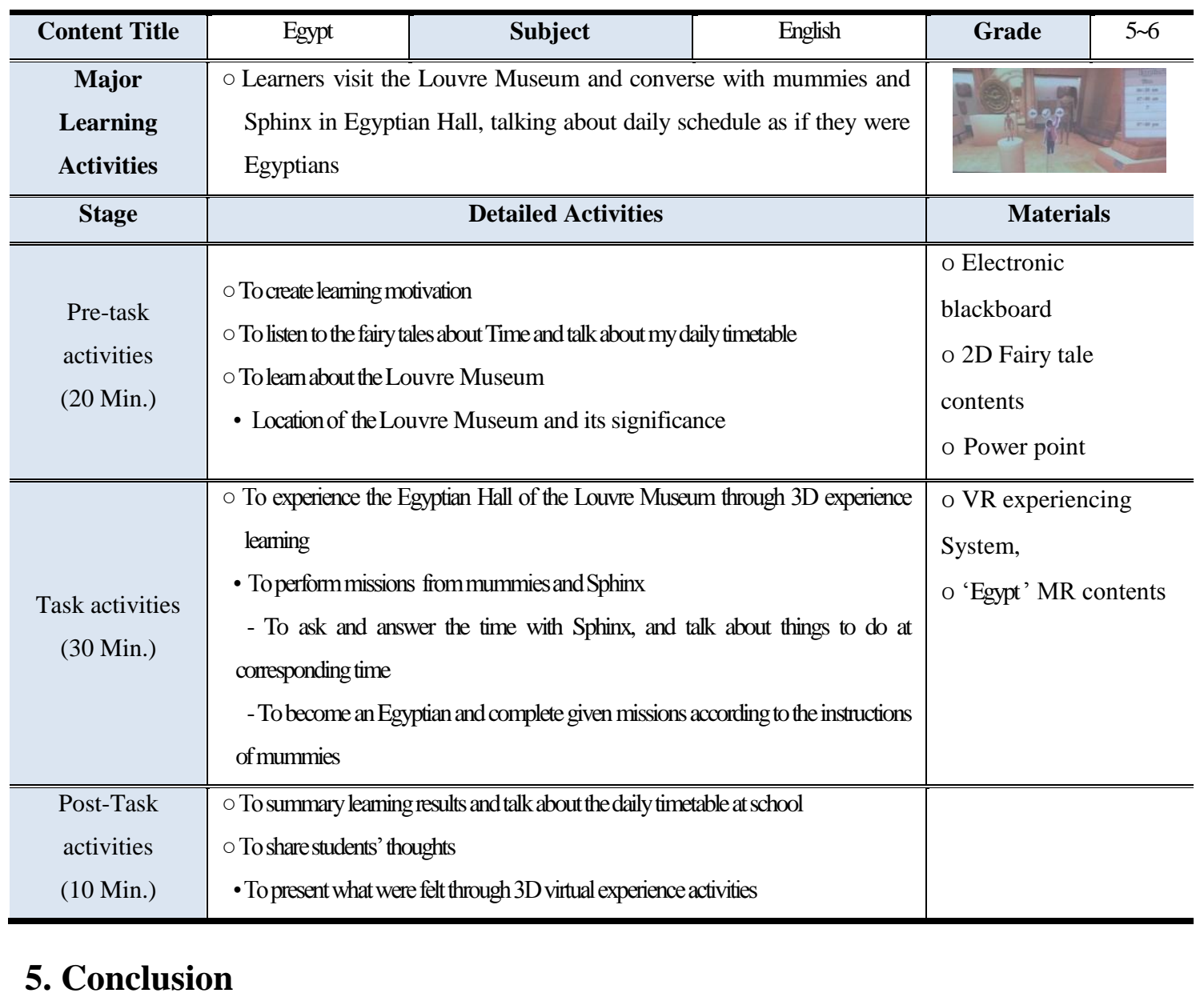

Experience learning Tesson plans using MR contents were proposed as the results of this study. To expand lesson utilizing MR contents, first it is needed to develop MR contents highly related to elementary standard curriculum. Second, VR experiencing system should be easy to use so that a teacher can lead the class while operating VR experiencing system. Moreover, it is needed provide lesson plans and system manuals and place teaching assistants. Lastly it is needed to evaluate the effectiveness of these learning activities using MR contents in further studies.

\section{Acknowledgements}

This work was supported by the Smart Education Model School Project of Korea Education and Research Information Service.

\section{References}

[1] J. Kim, K. Kim, M. Kim and S. Kim, "The Educational Effect of Augmented Reality based Learning", KERIS, Seoul, (2008). 
[2] M. Jo, J. Han, E. Hyun, G. Kim and N. Kim, "Development and Utilization of Projector-Robot Service for Children's Dramatic Play Activities based on Augmented Reality", Advanced in Information Science and Service Science, vol. 3, no. 5, (2011), pp. 277-288.

[3] K. F. Hew and W. S. Cheung, "Use of Three-Dimensional (3-D) Immersive Virtual Worlds in K-12 and Higher Education Settings: A Review of the Research", British Journal of Educational Technology, vol. 41, no. 1, (2010), pp. 33-55 .

[4] C. Kim and K. Kim, "The Effects of Experiential Learning based on Augmented Reality Method on the Learning of Storybooks and Involvement in Educational Activities for Preschool Children", The Journal of Korea Open Association for Early Childhood Education, vol. 16, no. 4, (2011), pp. 449-468.

[5] E. Hyun, K. Choi and H. Yeon, "Young Children's Response to Technological Components in Dramatic Activities Relying on Robot Projector based Augmented Reality", Korean Journal of Contents, vol. 12, no. 5, (2013), pp. 113-124 .

[6] H. Huang, U. Rauch and S. Liaw, "Investigating Learners' Attitudes Toward Virtual Reality Learning Environments: Based on a Constructivist Approach", Computers and Education, vol. 55, (2010), pp. 11711182.

[7] H. Suh, "Developing Learning Activities using Mixed Realtiy Contents at Elementary Smart School", Advanced Science and Technology Letters (Education), vol. 36, (2013) pp. 32-36,

[8] F. R. Shaftel, "Role Playing: An Approach to Meaningful Social Learning", Social Education, vol. 34, no. 5, (1970), pp. 556-559.

[9] R. J. Cabral, "Role Playing as a Group Intervention", Small Grout Research, vol/18, no. 4, (1987), pp. 470482.

[10] C. E. Hmelo-Silver, "The International Handbook of Collaborative Learning", Educational Psychology Handbook Series, (2013).

[11] D. Nunan, "Task-Based Language Teaching", Cambridge University Press, (2004).

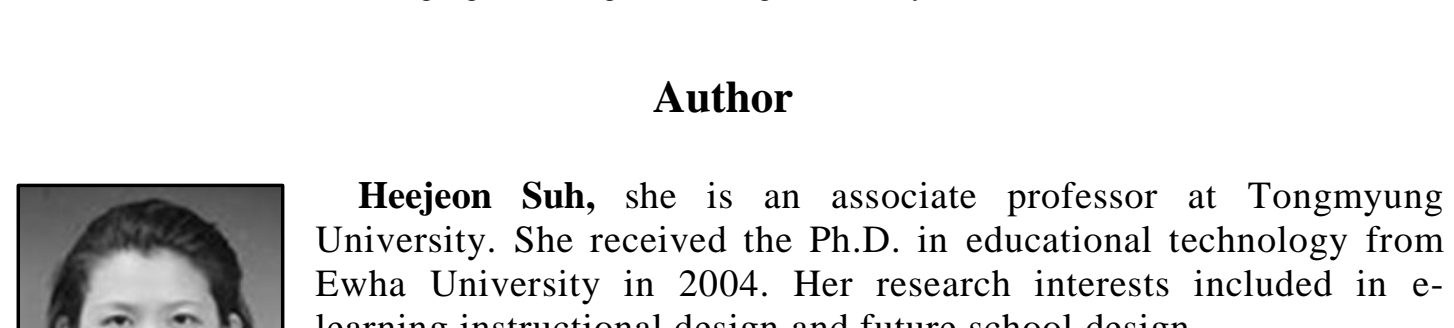
learnng instructional design and future school design. 
International Journal of Multimedia and Ubiquitous Engineering Vol.9, No.6 (2014)

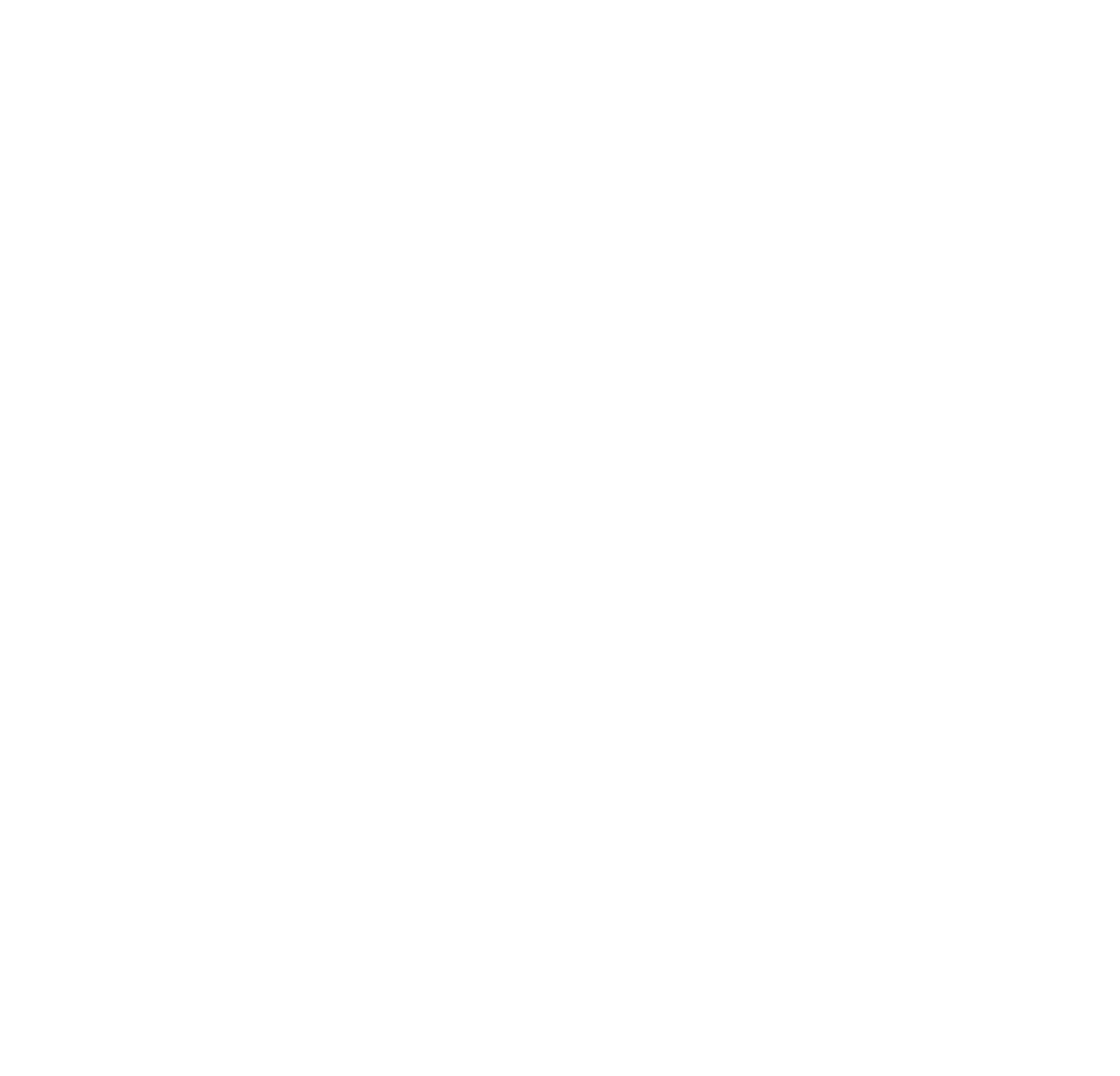

